\title{
A Comparative Study of Biogas Reactor Fluid Rheology-Implications for Mixing Profile and Power Demand
}

\author{
Luka Šafarič ${ }^{1, * \mathbb{C}}$, Sepehr Shakeri Yekta ${ }^{1}$, Jörgen Ejlertsson ${ }^{1,2}$, Mohammad Safari ${ }^{3}{ }^{10}$, \\ Hossein Nadali Najafabadi ${ }^{3}$, Anna Karlsson ${ }^{2}$, Francesco Ometto ${ }^{2}$, Bo H. Svensson ${ }^{1}$ and \\ Annika Björn ${ }^{1}$ \\ 1 Department of Thematic Studies-Environmental Change, Linköping University, \\ SE-581 83 Linköping, Sweden; sepehr.shakeri.yekta@liu.se (S.S.Y.); \\ jorgen.ejlertsson@scandinavianbiogas.com (J.E.); bo.svensson@liu.se (B.H.S.); annika.bjorn@liu.se (A.B.) \\ 2 Scandinavian Biogas Fuels AB, SE-111 60 Stockholm, Sweden; \\ anna.karlsson@scandinavianbiogas.com (A.K.); francesco.ometto@scandinavianbiogas.com (F.O.) \\ 3 Department of Management and Engineering, Linköping University, SE-581 83 Linköping, Sweden; \\ mohsa012@student.liu.se (M.S.); hossein.nadali.najafabadi@liu.se (H.N.N.) \\ * Correspondence: luka.safaric@liu.se
}

Received: 3 September 2019; Accepted: 30 September 2019; Published: 3 October 2019

\begin{abstract}
Anaerobic digestion (AD) is an established process for integrating waste management with renewable energy and nutrient recovery. Much of the research in this field focuses on the utilisation of new substrates, yet their effects on operational aspects such as fluid behaviour and power requirement for mixing are commonly overlooked, despite their importance for process optimisation. This study analysed rheological characteristics of samples from 21 laboratory-scale continuous stirred-tank biogas reactors (CSTBRs) digesting a range of substrates, in order to evaluate substrate effect on mixing efficiency and power demand through computational fluid dynamics (CFD). The results show that substrate and process parameters, such as solids content and organic loading, all have a significant effect on CSTBR fluid rheology. The correlation levels between rheological and process parameters were different across substrates, while no specific fluid behaviour patterns could be associated with substrate choice. Substrate should thus be considered an equally important rheology effector as process parameters. Additional substrate-related parameters should be identified to explain the differences in correlations between rheological and process parameters across substrate groups. The CFD modelling revealed that the rheology differences among the AD processes have significant implications for mixing efficiency and power demand of the CSTBRs, highlighting the importance of considering the substrate-induced effects on CSTBR rheology before including a new substrate.
\end{abstract}

Keywords: anaerobic digestion; viscosity; substrate; computational fluid dynamics; stirring

\section{Introduction}

Anaerobic digestion (AD) is an instrumental organic waste management technology for providing renewable energy in form of biogas and curbing the negative environmental impacts associated with conventional waste handling methods [1]. The biogas industry is expanding rapidly, as evident from the increasing trend in the number of newly constructed biogas plants over the last decade in Europe. The number of plants by the end of 2016 had almost tripled from 2009, bringing the total up to almost 18,000 [2]. In connection to this growing rate of development, the already available substrates for AD become intensely utilised, increasing the need for using novel substrates with diverse physicochemical properties, and introducing new challenges for the biogas industry. The most 
commonly used reactor type for AD in Europe is the continuous stirred-tank biogas reactor (CSTBR) [3]. The operational principles of CSTBRs require regular and efficient mixing of the digester sludge to bring the microorganisms in contact with the substrate, facilitate gas release, and distribute the heat evenly in the reactor [4]. Insufficient mixing intensities may lead to creation of "dead zones" [5], and sedimentation or flotation of different materials of the sludge [6]. Overly intense mixing negatively affects the sensitive syntrophic interactions between bacteria and archaea, as well as the colonisation of microorganisms on substrate particles, and ultimately leads to a decrease in the efficiency of the AD process $[7,8]$.

In addition, the energy input for mixing represents a substantial portion of the energy required for the operation of CSTBRs $[9,10]$ and accounts for a considerable part of operational costs at AD plants. The optimisation of mixing is therefore a central aspect for AD of organic wastes in CSTBRs with implications for both process performance and economy [11]. Higher apparent viscosities and more complex rheological behaviour should generally lead to increased power requirement and prolonged mixing time (i.e., the time required for the homogenisation of the entire reactor volume) [12], which affect energy consumption and AD process stability, respectively. The more complex rheological behaviour has implications for mixing efficiency and may cause a selective pressure on anaerobic microorganisms due to high shear forces across the active volume of the digester as a result of overly-intense mixing, or uneven substrate and temperature distribution due to suboptimal mixing intensities [4]. While the effects of substrate choice on the AD process performance, e.g., biogas production efficiency and process stability, are broadly studied, the operational aspects related to influence of substrate choice on the digester sludge rheology and mixing are often overlooked.

An example of a substrate-related parameter that has been found to be important for process performance and rheology in CSTBRs is the solids content. Besides their concentration, particularly the size distribution and surface area of organic particles have been found to play an important role in the efficiency of microbial hydrolysis of the substrate [13], as well as in the regulation of digester sludge rheology. The latter is, however, not always straightforward to evaluate, since different authors report different relationships between solids and rheological parameters. Previous research reported by Björn et al. (2018) [14] on rheology in biogas reactors digesting a selection of substrates revealed tendencies toward different rheological behaviour of the digester sludge for different substrate types. Furthermore, it was demonstrated that the type of substrates used in $\mathrm{AD}$ processes determines the importance of different process parameters for rheology in CSTBRs. For example, application of sewage sludge in $\mathrm{AD}$ processes was reported to lead to reactor fluid rheology that correlates well with their total solid (TS) and total volatile solid (TVS) contents, while co-digestion of combinations of organic wastes (e.g., food, slaughterhouse, or agricultural wastes) may result in an establishment of complex fluid behaviours, which cannot be simply associated with the solids content of the sludge [14]. Similarly, Battistoni (1997) [15], who compared the rheology of anaerobic sludges from reactors treating either the organic fraction of municipal solid waste (OFMSW), primary, or mixed sewage sludge, reported varying behaviour, depending on the substrate. More specifically, the relationship between TVS and rheological parameters followed a power-law and exponential correlation for sewage sludge and OFMSW, respectively. On the other hand, Mbaye et al. (2014) [16] evaluated the rheology of five reactors, digesting different substrates, and found that the rheology of their sludge was dependent mainly on the TS and TVS contents, regardless of their origin. Since CSTBR sludge is a complex mixture with interacting particles and soluble molecules, the mechanisms behind the different observed correlations described above are generally difficult to discern. Available information on the relationship between substrate composition and fluid behaviour in AD processes is still scarce and few studies have addressed the rheology of digester sludge from AD processes with different substrate profiles. Particularly, the potential effects of substrate origin and operational conditions on mixing efficiency and power demand are currently unexplored.

With advances in computational sciences and computer technology, the application of computational fluid dynamics (CFD) in anaerobic digestion processes has increased over the last two 
decades. CFD is considered a powerful tool for studying different aspects of AD reactor operation. Kelly and Gigas (2001) [17] used CFD for predicting behaviour of power-law fluids in the transitional flow regimes to propose methods of power number estimation. Zadghaffari et al. (2009) [18] used CFD for the prediction of mixing time, pumping number and power number in a stirred-tank with a six-blade Rushton turbine in the turbulent flow field. They validated their results against experiments. Sajjadi et al. (2016) [19] studied the effect of jet mixing of non-Newtonian fluids in order to reduce dead zones, concluding that the outlet and inlet points, and the specific power input affect the volume of the stagnant zones and the percentage of active materials that remain inside the digester. Through CFD investigations, Ameur (2016) [20] has shown that among different vessel shapes, spherical ones provide uniform flow in the entire vessel and lead to lowest energy consumption. Zhang et al. (2016) [21] did a comparison between the power number obtained from experimental data and the results of different turbulence models for the digestion of cattle manure and corn stover, considering the fluid as incompressible and pseudoplastic. Results showed that higher accuracy was obtained by using the standard $k-\varepsilon$ model. $\mathrm{Wu}$ (2010) [22] evaluated the mixing properties of a digester mixed by pumped circulation; however, the focus was put on the mixing intensity with respect to the mixing energy (related to power input) by analysing the effect of the rheological properties and proposing a scaling-up strategy. The same author presented an extended and more complete version of the previous article in which a multiphase (liquid and gas) model was considered instead of a single phase one [23]. Yapici et al. (2008) [24] used large eddy simulations (LES) to study the effects of impeller clearance and disc thickness on the power number and found that the power number decreased with decreasing clearance and increasing disc thickness. The study focused on the turbulent flow field in a water-filled tank generated by a Rushton turbine impeller. These types of studies are computationally intensive and may not be used for parametric studies. The comprehensive review paper by Sadino-Riquelme et al. (2018) [25] addresses the current state-of-the-art in using CFD in AD from various perspectives (including model specifications, multiphase flow, turbulent regimes, rheology characterization etc.) and made a general assessment of CFD applications in this context.

This study aims to elucidate the effects of substrate origin and operational parameters on rheology of CSTBR fluids in order to assess the implications of different rheological properties in AD processes for mixing efficiency and power demand. For this purpose, the fluid properties in 21 laboratory-scale CSTBRs with different substrate profiles were characterized using rheological measurements and the results were used as a basis for estimation of mixing profile and power demand using computational fluid dynamics (CFD). It was found that operational parameters, such as organic loading rate (OLR), TS, and TVS, as well as substrate choice, play an important role in CSTBR sludge rheology. In particular, it was observed that different substrates lead to different relationships between OLR, TS/TVS, and rheology. Increased TS/TVS nevertheless tended to result in fluids that behaved as pseudoplastic fluids with or without yield stress, while fluids with lower TS/TVS were more likely to behave as Newtonian fluids. The CFD analysis revealed that differences in the observed fluid behaviour would significantly affect the mixing efficiency and power demand within the individual reactors. Overall, the results revealed the significance of the effects of substrate composition on mixing efficiency and power demand, thus providing basic knowledge for future process optimisation.

\section{Materials and Methods}

\subsection{Sample Collection and Process Parameter Measurements}

Sludge samples were collected from 21 mesophilic $\left(37^{\circ} \mathrm{C}\right)$ laboratory-scale CSTBRs with a working volume of $4 \mathrm{~L}$, which were used within studies aimed at evaluating the feasibility of digesting different substrates. Substrates used in the reactors included four categories of organic wastes, with seven reactors processing agricultural waste $(\mathrm{AW})$, seven digesting mixtures of different wastes (co-digestion; $\mathrm{CD}$ ), four on food waste (FW), and three papermill waste (PM), reflecting the number of experiments performed within each substrate category. Each reactor is identified throughout the text with its 
two-letter substrate designation, followed by a specific numeral. The summarised OLRs and hydraulic retention times (HRT) of the sampled CSTBRs are given in Table 1. More detailed information is available in Table S1 in the Supplementary Materials. Process performances of the reactors were monitored by measuring biogas production, volatile fatty acid (VFA) concentrations, $\mathrm{pH}$, TS (\% of total mass), and TVS (\% of total mass). The solids content was determined in accordance with the Swedish standard method (SS-028113), whereby the weight of the samples was measured before and after drying at $105{ }^{\circ} \mathrm{C}$ for $20 \mathrm{~h}$ to obtain the TS, followed by burning the dried samples at $550{ }^{\circ} \mathrm{C}$ to calculate the TVS. The $\mathrm{pH}$ was monitored with an InoLab pH 7310 (WTW, Weilheim, Germany), and VFA concentrations measured by gas chromatography according to Jonsson and Borén (2002) [26]. Total biogas production was measured with gas meters working on the principle of fluid displacement (Ritter $\mathrm{GmbH}$, Bochum, Germany). Samples for rheology characterisation were obtained at the steady state operation of each reactor. For reactors CD12, PM1, CD16, and CD17, sampling was performed during two distinct steady-state occasions, since their operational conditions (e.g., OLR, HRT, TS, TVS, or $\mathrm{pH}$ ) varied over time.

Table 1. Type of feedstocks and operational conditions of sampled laboratory-scale biogas reactors. OLR: organic loading rate; HRT: hydraulic retention times; TS: total solid; TVS: total volatile solid.

\begin{tabular}{|c|c|c|c|c|c|c|}
\hline Group & $\begin{array}{l}\text { No. of } \\
\text { Reactors }\end{array}$ & 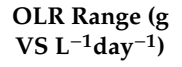 & $\begin{array}{l}\text { HRT Range } \\
\text { (Days) }\end{array}$ & $\begin{array}{l}\text { TS Range (\% of } \\
\text { Total Mass) }\end{array}$ & $\begin{array}{c}\text { TVS Range }(\% \text { of } \\
\text { Total Mass) }\end{array}$ & pH Range \\
\hline $\begin{array}{l}\text { Agricultural waste } \\
(\mathrm{AW})\end{array}$ & 7 & $2.5-7.0$ & $10-20$ & $1.6-7.7$ & $1.3-6.4$ & $7.2-7.9$ \\
\hline Co-digestion (CD) & 7 & $2.1-6.7$ & $16-31$ & $2.4-7.3$ & $1.5-4.6$ & $7.1-7.5$ \\
\hline Food waste (FW) & 4 & $5.5-8.2$ & $10-20$ & $3.7-5.3$ & $2.2-4.2$ & $6.7-8.0$ \\
\hline Paper mill waste (PM) & 3 & $3.0-3.7$ & $6-11$ & $2.6-11.2$ & $1.6-6.4$ & $7.3-7.6$ \\
\hline Total: & 21 & $2.0-8.2$ & $6-31$ & $1.6-11.2$ & $1.3-6.4$ & $6.7-8.0$ \\
\hline
\end{tabular}

\subsection{Rheology Analyses}

Rheological measurements were performed within 3 days after sampling at $37 \pm 0.2{ }^{\circ} \mathrm{C}$, corresponding to the operational temperatures of the CSTBRs. A shear rate controlled Searle-type rotational rheometer (RheolabQC SN80609650) equipped with a CC27-SN19237 measuring system and a C-LTD 80/QC cell, coupled with Rheoplus software (Anton Paar GmbH, Graz, Austria) was used for rheology analyses in accordance with the three-step protocol adapted from Pevere et al. [27]. Briefly, the three-step protocol was performed by (i) linearly increasing the shear rate from 0 to $800 \mathrm{~s}^{-1}$ for 800 $\mathrm{s}$ with a measuring point every $10 \mathrm{~s}$; (ii) keeping it at $800 \mathrm{~s}^{-1}$ for $300 \mathrm{~s}$, with a measurement taken at every $60 \mathrm{~s}$; and (iii) decreasing the shear rate again to $0 \mathrm{~s}^{-1}$ over a period of $800 \mathrm{~s}$ with measuring points at each $10 \mathrm{~s}$. The rheological models of Bingham, Ostwald, or Herschel-Bulkley [28] were applied to the data to determine the rheological parameters, including yield stress $\left(\tau_{0}\right)$, consistency index $(K)$, and flow behaviour index $(n)$. The optimal model to describe each fluid was selected based on the combination of least-square goodness of fit and the distribution of residuals, with the less parametrized model favoured whenever possible [28]. Limit viscosity (apparent viscosity at $800 \mathrm{~s}^{-1}$ ) was extracted and compared among the reactor liquids [29].

Correlations between the rheological parameters and $\mathrm{pH}, \mathrm{TS}$, TVS, OLR, HRT, and gas production, indicating the operational conditions of reactors, were studied by pairwise Pearson correlation analysis. Furthermore, K-means clustering of the samples was performed based on the parameters, $\tau_{0}, K$, and $n$ in order to group samples according to their rheological properties and evaluate potential correspondence of the rheological parameters with substrate type and process parameters. The clustering procedure began with the selection of rheological parameters which could significantly describe the rheograms (i.e., high $\mathrm{R}^{2}$ values and normal distribution of residuals). The parameters were standardised with the Z-score method before clustering [30]. Optimization of the number of clusters was performed according to the Calinski-Harabasz approach [31]. Thereafter, potential associations of specific clusters with differences in process parameters were evaluated by performing a Tukey honest significant difference test (Tukey HSD). 


\subsection{Computational Fluid Dynamics}

The rheological parameters from three samples with distinctly different fluid behaviours were used as inputs for CFD modelling in order to estimate mixing efficiency and power demand. The computational domain was chosen based on a laboratory-scale reactor geometry with a liquid height of $191 \mathrm{~mm}$ and diameter of $200 \mathrm{~mm}$. The mixing was performed with a central three-bladed $45^{\circ}$ pitched-blade impeller with a diameter of $120 \mathrm{~mm}$ and positioned $40 \mathrm{~mm}$ above the bottom of the reactor. To reduce the computational cost, 120 degrees of the full tank were simulated with an assumption of an axisymmetric flow throughout the fluid body, i.e., by modelling only one-third of the computational domain the need for mesh and thereby computations will be reduced by two-thirds.

The finite element-based solver Comsol Multiphysics V5.4 (COMSOL AB, Stockholm, Sweden) was used to solve the conservational laws of mass and momentum, i.e., continuity and momentum equations, Equations (1)-(2).

$$
\begin{gathered}
\nabla \cdot(V)=0 \\
\frac{\partial(\rho V)}{\partial t}=-\nabla \cdot(\rho V V)-\nabla p+\nabla \cdot \tau+\rho g
\end{gathered}
$$

where $\rho, p, V, g$, and $\tau$ respectively are the density, pressure, velocity, gravity and the stress tensor, which is defined as follows:

$$
\tau=\mu\left[(\nabla V)+(\nabla V)^{T}\right]=\mu D,
$$

where $D$ is the strain rate tensor. The apparent viscosity, $\mu$, of incompressible non-Newtonian fluids is a function of shear rate, $\dot{\gamma}$, which is defined as:

$$
\dot{\gamma}=\sqrt{\frac{1}{2}(D: D)}
$$

In order to calculate the apparent viscosity of the non-Newtonian fluid, it is necessary to present a rheological model for each type of non-Newtonian fluid. The viscosity for Newtonian fluids is as follows:

$$
\mu=\frac{\tau}{\dot{\gamma}}
$$

The apparent viscosity for power-law model is as follows:

$$
\mu=K \dot{\gamma}^{n-1},(n<1) .
$$

The apparent viscosity for Bingham model is as follows:

$$
\mu=\frac{\tau_{y}}{\dot{\gamma}}+K .
$$

The apparent viscosity for Herschel-Bulkley model is as follows:

$$
\mu=\frac{\tau_{y}}{\dot{\gamma}}+K|\dot{\gamma}|^{n-1}
$$

where $\tau_{y}, K$ and $n$ are the yield stress, the consistency index and the flow behaviour index, respectively.

The simulations were performed for mixing speeds between 50 and $300 \mathrm{rpm}$ for calculation of different Reynolds $(R e)$ numbers, and the no-slip boundary condition was assumed at the reactor wall. Although a typical anaerobic digester will be of multiple phases or states of matter, the flow was considered as single-phase and isothermal (implying temperature-independent properties) with Newtonian and non-Newtonian behaviours, based on the rheological modelling results. This assumption was made, since with multiphase modelling, limited knowledge on properties of all phases, such as gas bubble diameter, particles' sizes and densities, etc., can lead to increased uncertainty of 
the outcomes; see Wicklein et al. (2016) [32]. Moreover, the computational cost of multiphase flow simulations increases as additional equations need to be modelled. Therefore, it is common practice to consider the flow as single phase, although limitations of such assumption should be considered.

The multiple reference frame (MRF) was used to perform steady-state analysis of the impeller motion using laminar or turbulent flow, depending on the calculated Re (Table S2 in the Supplementary Materials). For turbulent regimes, in addition to the Reynolds-averaged Navier-Stokes (RANS) equations for the conservation of momentum and mass, the standard two-equation $k-\varepsilon$ model, developed by Launder and Spalding (1972) [33], with realizability constraints (to prevent excessive turbulence production) was used to model the turbulence effects, Equations (3)-(7).

$$
\begin{gathered}
\tau=\left(\mu+\mu_{T}\right)\left[(\nabla V)+(\nabla V)^{T}\right], \\
\rho(V . \nabla) k=\nabla \cdot\left[\left(\mu+\frac{\mu_{T}}{\sigma_{k}}\right) \nabla k\right]+P_{k}-\rho \varepsilon, \\
\rho(V . \nabla) \varepsilon=\nabla \cdot\left[\left(\mu+\frac{\mu_{T}}{\sigma_{\varepsilon}}\right) \nabla \varepsilon\right]+C_{\varepsilon 1} \frac{\varepsilon}{k} P_{k}-C_{\varepsilon 2} \rho \frac{\varepsilon^{2}}{k}, \\
\mu_{T}=\rho C_{\mu} \frac{k^{2}}{\varepsilon}, \\
P_{k}=\mu_{T}\left[\nabla V:\left(\nabla V+(\nabla V)^{T}\right)\right] .
\end{gathered}
$$

The $k-\varepsilon$ model is known to be suitable for mixing and swirl flows, and is one of the most commonly used turbulence models for industrial applications. According to Zhang et al. (2016) [21] this model could best predict the mixing in reactors compared to other turbulence models. The near wall flow is modelled through the wall function approach which allows for analytical expressions to compute the near wall flow region with relatively lower computational cost compared to low Re number approaches. The first order discretization scheme was used to discretize the equations of motions as well as the additional transport equations for turbulence modelling. The CFD model was validated using the experimental data from Saeed et al. (2008) [34]. The details of the validation procedure and outcomes are described in the Supplementary Materials (Text S1, Table S3, and Figures S3 and S4).

\section{Results and Discussion}

\subsection{Rheological Properties in CSTBRs with Different Substrate Profiles}

The limit viscosities of CSTBR fluids ranged from $<3$ to $62 \pm 1.3 \mathrm{mPa}$ s (Figure 1 ) and the fluid types, based on the corresponding rheological model parameters $\tau_{0}, k$, and $n$, were either Newtonian, Bingham plastic, pseudoplastic, or pseudoplastic with yield stress. More details on the specific modelling parameter values for each sample are presented in Appendix A (Table A1). The highest variability was observed in reactors digesting papermill waste, ranging from $<3$ to $56 \pm 1.6 \mathrm{mPa}$ s. These fluids exhibited Newtonian or Bingham plastic behaviours. Fluids of reactors digesting AW had limit viscosities between $4.6 \pm 0.2$ and $37 \pm 1.7 \mathrm{mPa}$ s and were Newtonian, except for one sample, which behaved as a pseudoplastic fluid with yield stress. Limit viscosities of fluids from reactors that co-digested combinations of substrates (CD) ranged from $3.5 \pm 0.3$ to $25.1 \pm 0.6 \mathrm{mPa}$ s and exhibited Newtonian, Bingham plastic, or pseudoplastic behaviours with- or without yield stress. The fluids from reactors digesting FW generally had relatively high limit viscosities, ranging from $6.2 \pm 0.3$ to 62 $\pm 1.3 \mathrm{mPa}$ s and behaved as Newtonian, Bingham plastic, or pseudoplastic fluids. 


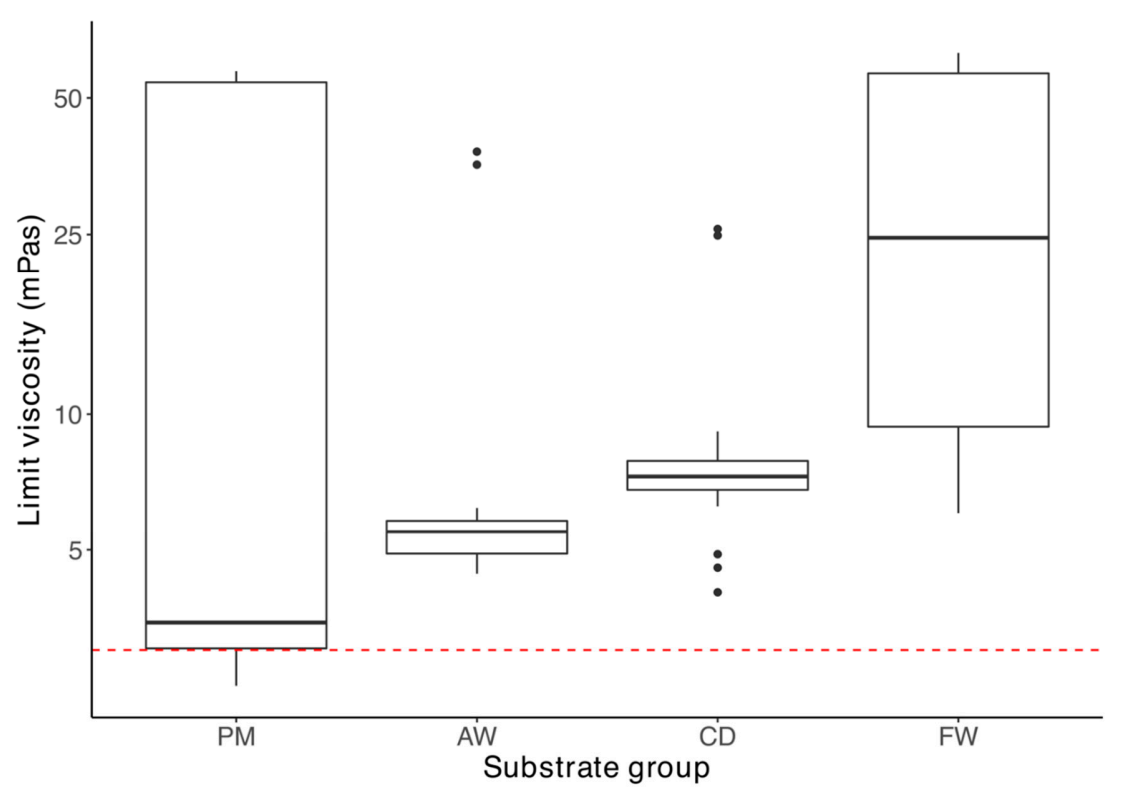

Figure 1. Limit viscosity (shear rate $800 \mathrm{~s}^{-1}$ ) values for fluids of continuous stirred-tank biogas reactors (CSTBRs) digesting different substrate groups: PM, papermill waste; AW, agricultural waste; CD, co-digestion; and FW, food waste. The red dashed line approximates the lower limit of the measuring range of the rheometer measuring system.

\subsection{Relationship between Rheological Properties and Operational Conditions}

The results of the correlation analysis revealed that relationships between rheological and process parameters were more profound within each substrate group than those across all samples. The TVS content of the samples from PM-digesting CSTBRs corresponded well to the limit viscosities (Pearson correlation $r=1.0, p<0.001$ ). However, it is emphasized that the combination of relatively low number of samples (i.e., four) and an uneven TVS representation (i.e., one case with a much higher value of TVS than the others) may limit the generalization of these results for other AD systems with PM as their main substrate. For samples from AW digesters, a significant positive correlation of limit viscosity with OLR and TVS was observed (Pearson correlation, $r=0.90, p<0.001$, and $r=0.90, p<0.001$, respectively). For the CD digesters, OLR, TS, and TVS correlated significantly with yield stress (Pearson correlations, $r=0.85, r=0.94$, and 0.89 , respectively at $p<0.05$ ). The limit viscosity of fluids from co-digesters correlated well with TVS (Pearson correlation, $r=0.86, p<0.05$ ), and the consistency index of rheological models $(K)$ was found to correlate negatively with $\mathrm{pH}$ (Pearson correlation, $r=-0.96$, $p<0.05)$. Correlations between $\mathrm{pH}$ and rheological parameters, specifically apparent viscosities, have been obtained previously in studies of activated sludge by Sanin (2002) [35] and Tixier et al. (2003) [36], but in their cases the correlation was positive. Our finding suggests that the rheological dependence on $\mathrm{pH}$ is a likely feature of anaerobic digesters. However, the relationship is likely different due to the inherent differences in sludge structure, as well as the effect of $\mathrm{pH}$ on the AD process itself, as opposed to its direct effects on rheology, reported by Sanin (2002) [35] and Tixier et al. (2003) [36].

Considering that differentiation between the effects of solids content and substrate on rheology is not straightforward, as well as that process parameters correlate differently with rheological parameters depending on substrate, it is evident that process parameters other than OLR, TS, and TVS, but which are related to specific substrates, play an important role. Similar observations of specific sludge types exhibiting different behaviour were reported by Lotito and Lotito (2014) [37], who found that sludges from different parts of the wastewater treatment process (activated sludge, sewage sludge, and digestate) behaved differently from one another even at equal solids content. The choice of specific substrate may possibly affect the rheology of the resulting sludge through process parameters not monitored in this study. Including a broader range of process parameters would therefore enhance 
the likelihood of capturing those that would help explain the differences observed. Candidates for further investigation are, for example, particle size distribution and surface charge [38], which are likely dependent on substrate choice.

\subsection{Fluid Clustering}

Optimization of the number of clusters, comprising samples with similar rheological properties by the K-means clustering algorithm, indicated that designation of the samples into six groups is optimal for this dataset (Figure S1 in the Supplementary Materials). The majority of clusters did not appear to correspond to any discernible pattern in terms of substrate composition (Table 2). Exceptions were clustering of two samples from FW digesters with the highest consistency indices (i.e., Cluster 1 in Table 2). These fluids were strongly pseudoplastic but did not exhibit a yield stress. The samples within this cluster were characterised by some of the lowest $\mathrm{pH}$ values in the dataset, high OLR, and relatively high solids content (Table 2, and Figures S2a-d in the Supplementary Materials). However, differences in these parameters were not statistically significant between the clusters (Tukey HSD test, $p>0.05)$, which was likely a consequence of low sample numbers in each cluster. Samples in Cluster 3 demonstrated relatively complex rheological behaviour of pseudoplasticity with yield stress and were associated with AD processes with relatively high OLR and solids content. On the other hand, the clusters containing samples with the lowest limit viscosities and simplest rheological behaviours (Clusters 2, 5, and 6) were generally related to lower OLR and solids content (Table 2). Accordingly, higher OLR and TS/TVS may be associated with high values of rheological parameters and a more complex fluid behaviour in AD processes. Interactions between OLR, TS/TVS, and rheology, have been reported before in the literature [39]. The apparent connection between OLR and TS/TVS may be due to increased OLR naturally leading to the introduction of a higher concentration of particles into the system. These particles could in turn affect rheology, partially as described by Einstein's equation of viscosity of dispersions [40], by absorbing some of the energy that would otherwise have been directed to fluid flow for inducing their motion. The fact that the individual clusters to some extent overlap in their solids content and OLR, despite exhibiting differing fluid behaviour, suggests that additional operational parameters related to each specific substrate may also play an important role in these interactions. Nevertheless, these results highlight that increasing the OLR generally leads to increased effects of the substrate on the rheology of CSTBR sludge. More specifically, it will most likely lead to increased TS/TVS contents, which will affect the rheology to a differing degree, depending on the characteristics of the specific substrate.

Table 2. K-means clustering results. Reactor names are composed of the two-letter substrate designation and a specific numeral. Lowercase "s" stands for the second sampling from the same reactor. PM, paper mill waste; AW, agricultural waste; $\mathrm{CD}$, co-digestion; and FW, food waste, respectively.

\begin{tabular}{|c|c|c|c|c|c|c|}
\hline Cluster & 1 & 2 & 3 & 4 & 5 & 6 \\
\hline \multirow{4}{*}{ Sample } & FW3 & AW8 & AW2 & CD12 & CD17 & AW3 \\
\hline & FW4 & CD21 & CD14 & CD12s & CD17s & FW1 \\
\hline & & PM1s & CD15 & CD16 & FW2 & PM1 \\
\hline & & & & $\begin{array}{l}\text { CD16s } \\
\text { PM3 }\end{array}$ & & \\
\hline $\begin{array}{l}\text { Main rheological } \\
\text { characteristics }\end{array}$ & $\begin{array}{c}\mathrm{K}>2.5 \\
\text { Pseudopla-stic }\end{array}$ & $\begin{array}{l}\text { Bingham plastic } \\
\text { (Newtonian) }\end{array}$ & $\begin{array}{l}\text { Pseudoplastic with } \\
\text { yield stress }\end{array}$ & $\begin{array}{l}\text { Bingham } \\
\text { plastic }\end{array}$ & $\begin{array}{l}\text { Bingham plastic } \\
\text { (low yield stress) }\end{array}$ & Newto-nian \\
\hline OLR $\left(\right.$ g VS L $\left.^{-1} d^{-1}\right)$ & $6.9 \pm 1.9$ & $3.2 \pm 0.8$ & $5.9 \pm 1.7$ & $3.3 \pm 1.2$ & $3.8 \pm 2.9$ & $4.3 \pm 1.5$ \\
\hline TS $(\%$ total $)$ & $5.1 \pm 0.3$ & $3.2 \pm 0.6$ & $6.2 \pm 2.3$ & $5.5 \pm 3.2$ & $3.9 \pm 0.5$ & $3.1 \pm 0.5$ \\
\hline TVS (\% total) & $3.8 \pm 0.6$ & $2.1 \pm 0.6$ & $4.6 \pm 1.8$ & $3.4 \pm 1.8$ & $2.2 \pm 0.4$ & $2.1 \pm 0.4$ \\
\hline $\mathrm{pH}$ & $6.9 \pm 0.3$ & $7.6 \pm 0.3$ & $7.2 \pm 0.2$ & $7.3 \pm 0.2$ & $7.6 \pm 0.3$ & $7.4 \pm 0.2$ \\
\hline
\end{tabular}

\subsection{Mixing Profiles and Power Demand}

The CFD modelling was performed for samples of reactors AW3, FW4, and PM3 at different stirring speeds. These three specific samples were selected to represent a Newtonian fluid with low $K$, a pseudoplastic fluid with high $K$, and a Bingham plastic fluid with high yield stress, respectively. The results revealed that the extent of differences in rheological behaviour led to significantly different 
mixing profiles and power requirements (Figure 2). Logarithmic scale was used to provide more distinct visualization of shear rate differences. Log shear rates higher than 0 indicate different levels of dynamic zones, whereas lower values are associated with dead-zone regions. Streamlines can represent recirculation, mixing zones, and existence of flow gradients. Based on the CFD modelling results, AW3 fluid sustains mixing to upper parts of the reactor (i.e., log shear rates higher than zero), while the other two cases, FW4 and PM3, do not. Thus, both FW4 and PM3 contain a larger volume of dead zones in the tanks indicated by stagnant and low shear rates (Figure 2). Furthermore, the in-plane streamlines indicate a rotating flow around the impeller for the AW3 case, which leads to improved mixing properties. The yield stress acts as an inertia force opposite to the motion of the fluid depending on the fluid behaviour being laminar or turbulent. It is worth mentioning that the effect of yield stress on the shear rate is independent of the rotational speed of the impeller, whereas the roles of $K$ and $n$ indices vary based on the rotational speed of the impeller. Accordingly, the lack of yield stress for AW3 and the turbulent flow regime explains the relatively uniform and larger dynamic zone for this rheological case. Although increasing the rotational speed improves the mixing behaviour for all cases, case AW3 will have a much more uniform mixing, while the rheological properties of PM3 promote a large dead zone volume even at highest stirring speed due to the high yield stress associated with this fluid. This implies that complete mixing with the assumed reactor geometry would be impossible when digesting the substrate of PM3, which could have severe consequences for the AD process stability. For the rheological case FW4, on the other hand, the dynamic zone around the impeller expands more significantly at higher stirring speeds; however, this resulted in a very non-uniform mixing behaviour, as observed from shear rate changes from high to low and then to high again from near the impeller towards the top of the tank.

Figure 3A illustrates the power number $\left(N_{p}\right)$ as a function of Re for the different rheological cases. The slope of the relationship between $N_{p}$ and Re declines as Re increases. For Re in the range of 100 up to 1000 a plateau is reached for $N_{p}$, in line with previous studies, as reviewed by Geankoplis (1993) [41]. These regions are associated to the transitional flow (i.e., the transition between laminar and turbulent flow). For turbulent flow regimes, the decrease in $N_{p}$ continues by increase in $R e$. The behaviour and ranges of values for rheological cases FW4 and PM3 are quite similar (Figure 3A), implying that the difference in consistency index $K$ between these cases, does not affect their power numbers. This is consistent with findings by Kelly and Gigas (2003) [17], who found that at aiven $R e$ and $n, N_{p}$ is not a function of $K$ for shear-thinning fluids. Due to the high $R e$ found for AW3, its $N_{p}$ is relatively low compared to the other two cases, and the impact of increasing Re will become less significant.

Figure 3B depicts the estimated total power demand as rotational speed increases. It is evident from the figure that the total power for case FW4 is lower than PM3 in lower speeds. As K for FW4 is higher than for PM3, the total power of FW4 becomes higher for rotational speeds above $225 \mathrm{rpm}$. Thus, the impact of $K$ on total power and shear rate is much more pronounced in higher rotational speeds. The case of AW3 showed the lowest total power consumption for all investigated rotational speeds. It should be noted that the exact values of the estimates are dependent on the underlying simplifying assumptions, including the shape, size, and positions of the impeller; the stirring speed; and the size of the reactor. Furthermore, the additional power required to compensate for friction and other losses was not considered. Nevertheless, the application of the same assumptions for comparison of different fluid types allows for a relevant comparison of the effects of rheology on mixing efficiency and power demand. Note that $R e$ is an important dynamic parameter used to effectively scale models compared to their prototypes. Thus, the important flow characteristics such as mixing efficiency (also power demand derived from flow variables) can represent the true scale prototype under the same $R e$ and geometric similarities, i.e., fulfilling the kinematic similarity. Accordingly, the results in this study are transferable to industrial-scale CSTBR systems, as long as the ratios between the impeller and reactor vessel dimensions are preserved. 
The approach described in this paper provides the background needed for process optimisation for improved mixing efficiency and reduced power consumption, which are prerequisites for efficient biogas production.

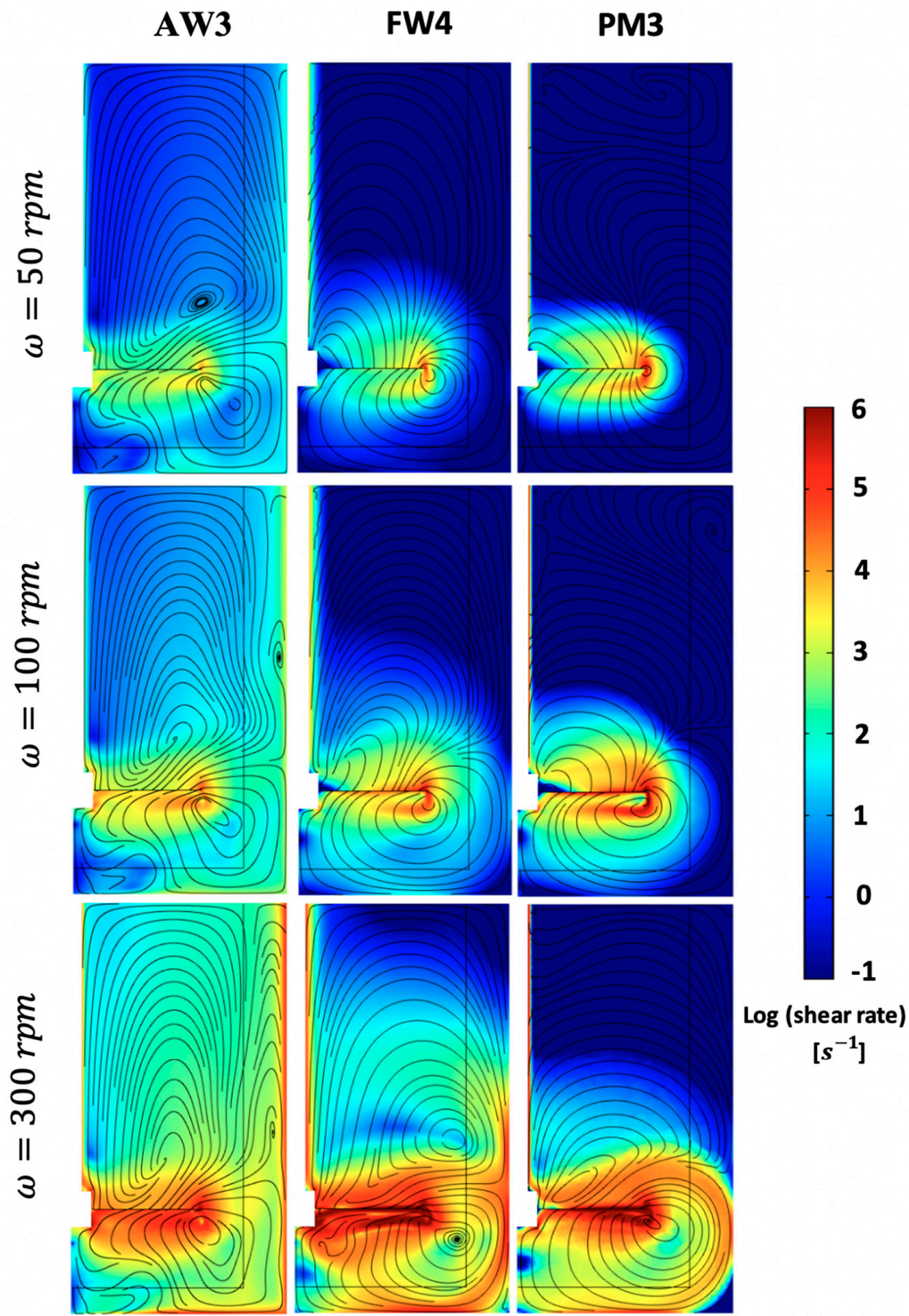

Figure 2. Logarithmic shear rate contours and in-plane streamlines for different rheological cases. From left to right: AW3 (agricultural waste), FW4 (food waste), and PM3 (paper mill waste), respectively. From top to bottom: rotational speeds of 50, 100, and $300 \mathrm{rpm}$, respectively. Each image represents a cross-section of half of the reactor, with the stirrer positioned on the left edge. 
A

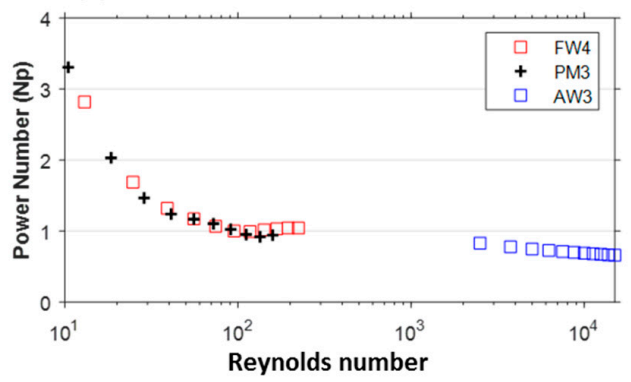

B

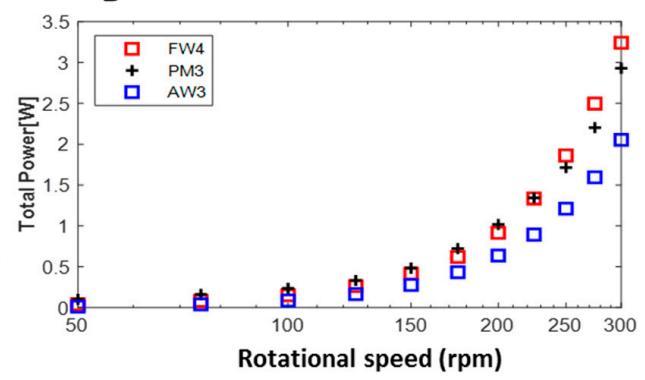

Figure 3. (A) Power number $\left(N_{p}\right)$ behaviours as function of Reynolds number $(R e)$ for different rheological cases. (B) Total power demand (W) as function of rotational speed of the impeller (rpm) for different rheological cases. FW, food waste; PM, paper mill waste; and AW, agricultural waste.

\section{Conclusions}

This study evaluated the importance of substrate types and process parameters for the rheology of CSTBR fluids and the resulting implications for mixing efficiency and power demand. One of the main findings was that commonly monitored process parameters, such as TS, TVS, OLR, and pH seem to correlate better with rheological behaviour within specific substrate groups than across all samples. This indicates that generalisations across reactors digesting different substrates should be avoided when studying CSTBR sludge rheology. While specific predictive assumptions of rheological behaviour based on the substrate composition could not be made, it is possible that the substrates impose physical characteristics on the particles in the reactor sludge, which then interact in distinct ways. Future research should therefore focus on identifying and quantifying the effects of specific substrate characteristics governing CSTBR sludge rheology.

In general, sludge exhibiting more complex rheological behaviours (i.e., pseudoplasticity and/or yield stress) tended to be associated with higher OLR (i.e., mostly above $5 \mathrm{~g} \mathrm{VS} \mathrm{L}^{-1}$ day $^{-1}$ ) than those with Newtonian or Bingham plastic fluid behaviour. The mechanism behind this is likely related to the higher observed TS and TVS content of these reactor fluids.

The CFD modelling revealed that the variation in observed rheological characteristics had significant practical implications, since the differences in required mixing power demands were substantial. Furthermore, the simulations showed that particularly in the case with high yield-stress values, complete mixing would not be attainable even at the highest simulated impeller speed, which would most likely affect the AD process efficiency. Cases with similar rheologies to PM3 or FW4 would therefore benefit more from pre-treatment approaches (e.g., mechanical, thermal, or chemical) with the purpose of improving their rheological characteristics than cases where the rheology is closer to that of AW3. The findings also highlight the importance of this type of information for biogas reactor design and operation, since over-engineering may be avoided by knowing the substrate-imposed ranges of power requirements needed for reactor operation. Overall, a deeper understanding of the fundamental mechanisms behind CSTBR sludge rheology is needed. This involves studying of other important process parameters, such as those related to substrate composition (e.g., particle size distribution, shape, and surface charge). Important parameters should be identified and their effects on the rheology quantified in order to enable a more accurate prediction of power demands.

Supplementary Materials: The following are available online at http://www.mdpi.com/2227-9717/7/10/700/s1, Table S1: Overview of all samples and the related operational and process parameters, Table S2: Overview rheological and computational fluid dynamics (CFD) modelling results for the three selected example fluids that were used for CFD analysis, Table S3: Mesh independence study performed for rheological case AW3, rotational speed of 300, corresponding to Re of $1.5 \times 10^{4}$, Figure S1: Results of clustering evaluation. (a), Calinski criterion values at different cluster numbers; (b), Multidimensional scaling visualisation of the 6 clusters, Figure S2a-d: Boxplots of process parameter associations with specific fluid clusters, Figure S3: The computational mesh of the CFD model, Figure S4: CFD validation for ranges of Reynold number in terms of power number, Text S1: CFD model verification and validation. 
Author Contributions: Conceptualization, L.Š., S.S.Y., J.E., M.S., H.N.N., A.K. and A.B.; Data curation, L.Š.; Formal analysis, L.Š. and M.S.; Funding acquisition, B.H.S. and A.B.; Investigation, L.̌̌., F.O. and A.B.; Methodology, L.Š., M.S., H.N.N. and A.B.; Project administration, B.H.S. and A.B.; Resources, J.E., A.K. and F.O.; Supervision, S.S.Y., H.N.N., B.H.S. and A.B.; Validation, M.S. and H.N.N.; Visualization, L.Š., M.S. and H.N.N.; Writing-original draft, L.Š.; Writing—review \& editing, L.Š., S.S.Y., J.E., M.S., H.N.N., A.K., F.O., B.H.S. and A.B.

Funding: This work was supported by the European Commission (Grant Agreement n. 316838 ATBEST), the Swedish Research Council Formas (Grant Agreement n. 2016-01054), and the Swedish Innovation Agency (Grant Agreement n. 2008-139).

Acknowledgments: The authors would like to thank the laboratory staff operating the lab-scale reactors for assistance during sampling and for providing information about the processes and substrates.

Conflicts of Interest: The authors declare no conflict of interest. The funders had no role in the design of the study; in the collection, analyses, or interpretation of data; in the writing of the manuscript, or in the decision to publish the results.

\section{Appendix A}

Table A1. Overview rheological modelling results. The sample names denote separate reactors. When the same reactor was sampled twice, the second sample is marked with an "s" behind the name.

\begin{tabular}{|c|c|c|c|c|c|c|c|}
\hline \multirow{2}{*}{ Sample } & \multirow{2}{*}{$\mathbf{N}$} & \multirow{2}{*}{ Flow Behaviour } & \multirow{2}{*}{$\begin{array}{c}\text { Rheological } \\
\text { Model }\end{array}$} & \multicolumn{4}{|c|}{ Model Parameters } \\
\hline & & & & $\tau_{0}$ & $K$ & $n$ & $\mathbf{R}^{2}$ \\
\hline AW2 & 2 & Pseudoplastic $+\tau_{0}$ & Her-Bul & 2.5802 & 0.4106 & 0.6217 & 0.99 \\
\hline a AW3 & 2 & Newtonian & Bingham & -0.0012 & 0.0048 & I & 0.93 \\
\hline b AW4 & 2 & Newtonian & & & & & \\
\hline b AW5 & 2 & Newtonian & & & & & \\
\hline b AW6 & 2 & Newtonian & & & & & \\
\hline b AW7 & 2 & Newtonian & & & & & \\
\hline AW8 & 2 & Bingham plastic & Bingham & 0.1920 & 0.0056 & / & 0.94 \\
\hline $\mathrm{CD} 12$ & 2 & Bingham plastic & Bingham & 0.9492 & 0.0056 & 1 & 0.93 \\
\hline CD12s & 2 & Bingham plastic & Bingham & 0.8765 & 0.0052 & / & 0.95 \\
\hline CD14 & 3 & Pseudoplastic $+\tau_{0}$ & Her-Bul & 0.5538 & 0.0394 & 0.7477 & 0.99 \\
\hline CD15 & 2 & Pseudoplastic $+\tau_{0}$ & Her-Bul & 2.2308 & 0.4210 & 0.5418 & 0.91 \\
\hline CD16 & 3 & Bingham plastic & Bingham & 0.7103 & 0.0050 & I & 0.92 \\
\hline CD16s & 3 & Bingham plastic & Bingham & 0.7062 & 0.0057 & I & 0.95 \\
\hline CD17 & 3 & Bingham plastic & Bingham & 0.6880 & 0.0059 & / & 0.97 \\
\hline CD17s & 3 & Bingham plastic & Bingham & 0.5107 & 0.0057 & / & 0.98 \\
\hline b CD19 & 1 & Newtonian & & & & & \\
\hline CD21 & 2 & Bingham plastic & Bingham & 0.2517 & 0.0062 & / & 0.98 \\
\hline${ }^{\mathrm{a}} \mathrm{FW} 1$ & 2 & Newtonian & Bingham & -0.0505 & 0.0056 & I & 0.92 \\
\hline FW2 & 2 & Bingham plastic & Bingham & 0.4874 & 0.0109 & / & 0.98 \\
\hline FW3 & 2 & Pseudoplastic & Ostwald & I & 2.5282 & 0.4166 & 1.00 \\
\hline FW4 & 2 & Pseudoplastic & Ostwald & / & 2.9333 & 0.4125 & 1.00 \\
\hline a PM1 & 3 & Newtonian & Bingham & -0.4784 & 0.0029 & / & 0.91 \\
\hline PM1s & 1 & Bingham plastic & Bingham & 0.2220 & 0.0037 & / & 0.98 \\
\hline b PM2 & 2 & Newtonian & & & & & \\
\hline PM3 & 3 & Bingham plastic & Bingham & 18.1211 & 0.0316 & / & 0.96 \\
\hline
\end{tabular}

$\mathrm{N}$ indicates the number of replicate samples used for all analyses. Her-Bul indicates the Herschel-Bulkley model. $\tau_{0}, K$, and $n$ correspond to the modelling parameters (yield stress, consistency index, and flow index, respectively).

a The negative values for $\tau_{0}$ are an artefact due to noise in the data and should be considered to be equal to 0 .

$\mathrm{b}$ Rheological modelling was not performed for these samples due to very low values throughout the rheogram.

\section{References}

1. Weiland, P. Biogas production: Current state and perspectives. Appl. Microbiol. Biotechnol. 2010, 85, 849-860. [CrossRef] [PubMed]

2. Deremince, B.; Königsberger, S. Statistical Report of the European Biogas Association 2017; European Biogas Association: Brussels, Belgium, 2017.

3. Kampman, B.; Leguijt, C.; Scholten, T.; Tallat-Kelpsaite, J.; Brückmann, R.; Maroulis, G.; Lesschen, J.P.; Meesters, K.; Sikirica, N.; Elbersen, B. Optimal Use of Biogas from Waste Streams An Assessment of the Potential of Biogas from Digestion in the EU Beyond 2020; European Comission: Brussels, Belgium, 2016.

4. Lindmark, J.; Thorin, E.; Bel Fdhila, R.; Dahlquist, E. Effects of mixing on the result of anaerobic digestion: Review. Renew. Sustain. Energy Rev. 2014, 40, 1030-1047. [CrossRef] 
5. Subramanian, B.; Pagilla, K.R. Mechanisms of foam formation in anaerobic digesters. Colloids Surf. B Biointerfaces 2015, 126, 621-630. [CrossRef] [PubMed]

6. Lienen, T.; Kleyböcker, A.; Brehmer, M.; Kraume, M.; Moeller, L.; Görsch, K.; Würdemann, H. Floating layer formation, foaming, and microbial community structure change in full-scale biogas plant due to disruption of mixing and substrate overloading. Energy. Sustain. Soc. 2013, 3, 20. [CrossRef]

7. Sindall, R.; Bridgeman, J.; Carliell-Marquet, C. Velocity gradient as a tool to characterise the link between mixing and biogas production in anaerobic waste digesters. Water Sci. Technol. 2013, 67, 2800-2806. [CrossRef] [PubMed]

8. Kim, M.; Kim, B.C.; Choi, Y.; Nam, K. Minimizing mixing intensity to improve the performance of rice straw anaerobic digestion via enhanced development of microbe-substrate aggregates. Bioresour. Technol. 2017, 245, 590-597. [CrossRef]

9. Dachs, G.; Rehm, W. Der Eigenstromverbrauch von Biogasanlagen und Potenziale zu dessen Reduzierung; Solarenergieförderverein Bayern e.V. (SeV): München, Germany, 2006.

10. Lindkvist, E.; Johansson, M.; Rosenqvist, J. Methodology for Analysing Energy Demand in Biogas Production Plants-A Comparative Study of Two Biogas Plants. Energies 2017, 10, 1822. [CrossRef]

11. Naegele, H.J.; Lemmer, A.; Oechsner, H.; Jungbluth, T. Electric energy consumption of the full scale research biogas plant "unterer lindenhof": Results of longterm and full detail measurements. Energies 2012, 5, 5198-5214. [CrossRef]

12. Nienow, A.W. Stirring and stirred-tank reactors. Chem. Ing. Tech. 2014, 86, 2063-2074. [CrossRef]

13. Palmowski, L.M.; Müller, J.A. Influence of the size reduction of organic waste on their anaerobic digestion. Water Sci. Technol. 2000, 41, 155-162. [CrossRef]

14. Björn, A.; Šafarič, L.; Karlsson, A.; Danielsson, Å.; Ejlertsson, J.; Svensson, B.H.; Shakeri Yekta, S. Substrate and operational conditions as regulators of fluid properties in full-scale continuous stirred-tank biogas reactors-Implications for rheology-driven power requirements. Water Sci. Technol. 2018, 78, 814-826. [CrossRef] [PubMed]

15. Battistoni, P. Pre-treatment, measurement execution procedure and waste characteristics in the rheology of sewage sludges and the digested organic fraction of municipal solid wastes. Water Sci. Technol. 1997, 36, 33-41. [CrossRef]

16. Mbaye, S.; Dieudé-Fauvel, E.; Baudez, J.C. Comparative analysis of anaerobically digested wastes flow properties. Waste Manag. 2014, 34, 2057-2062. [CrossRef] [PubMed]

17. Kelly, W.; Gigas, B. Using CFD to predict the behavior of power law fluids near axial-flow impellers operating in the transitional flow regime. Chem. Eng. Sci. 2003, 58, 2141-2152. [CrossRef]

18. Zadghaffari, R.; Moghaddas, J.S.; Revstedt, J. A mixing study in a double-Rushton stirred tank. Comput. Chem. Eng. 2009, 33, 1240-1246. [CrossRef]

19. Sajjadi, B.; Raman, A.A.A.; Parthasarathy, R. Fluid dynamic analysis of non-Newtonian flow behavior of municipal sludge simulant in anaerobic digesters using submerged, recirculating jets. Chem. Eng. J. 2016, 298, 259-270. [CrossRef]

20. Ameur, H. Agitation of yield stress fluids in different vessel shapes. Eng. Sci. Technol. Int. J. 2016, 19, $189-196$. [CrossRef]

21. Zhang, Y.; Yu, G.; Yu, L.; Siddhu, M.A.H.; Gao, M.; Abdeltawab, A.A.; Al-Deyab, S.S.; Chen, X. Computational fluid dynamics study on mixing mode and power consumption in anaerobic mono- and co-digestion. Bioresour. Technol. 2016, 203, 166-172. [CrossRef]

22. Wu, B. Computational fluid dynamics investigation of turbulence models for non-newtonian fluid flow in anaerobic digesters. Environ. Sci. Technol. 2010, 44, 8989-8995. [CrossRef]

23. Wu, B. CFD simulation of gas and non-Newtonian fluid two-phase flow in anaerobic digesters. Water Res. 2010, 44, 3861-3874. [CrossRef]

24. Yapici, K.; Karasozen, B.; Schäfer, M.; Uludag, Y. Numerical investigation of the effect of the Rushton type turbine design factors on agitated tank flow characteristics. Chem. Eng. Process. Process Intensif. 2008, 47, 1340-1349. [CrossRef]

25. Sadino-Riquelme, C.; Hayes, R.E.; Jeison, D.; Donoso-Bravo, A. Computational fluid dynamic (CFD) modelling in anaerobic digestion: General application and recent advances. Crit. Rev. Environ. Sci. Technol. 2018, 48, 39-76. [CrossRef] 
26. Jonsson, S.; Boren, H. Analysis of mono- and diesters of o -phthalic acid by solid-phase extractions with polystyrene-Divinylbenzene-based polymers. J. Chromatogr. A 2002, 963, 393-400. [CrossRef]

27. Pevere, A.; Guibaud, G.; van Hullebusch, E.; Lens, P. Identification of rheological parameters describing the physico-chemical properties of anaerobic sulphidogenic sludge suspensions. Enzym. Microb. Technol. 2007, 40, 547-554. [CrossRef]

28. Ratkovich, N.; Horn, W.; Helmus, F.P.; Rosenberger, S.; Naessens, W.; Nopens, I.; Bentzen, T.R. Activated sludge rheology: A critical review on data collection and modelling. Water Res. 2013, 47, 463-482. [CrossRef]

29. Tixier, N.; Guibaud, G.; Baudu, M. Determination of some rheological parameters for the characterization of activated sludge. Bioresour. Technol. 2003, 90, 215-220. [CrossRef]

30. Mohamad, I.B.; Usman, D. Standardization and its effects on K-means clustering algorithm. Res. J. Appl. Sci. Eng. Technol. 2013, 6, 3299-3303. [CrossRef]

31. Calinski, T.; Harabasz, J. A Dendrite Method For Cluster Analysis. Commun. Stat. 1974, 3, 1-27.

32. Wicklein, E.; Batstone, D.J.; Ducoste, J.; Laurent, J.; Griborio, A.; Wicks, J.; Saunders, S.; Samstag, R.; Potier, O.; Nopens, I. Good modelling practice in applying computational fluid dynamics for WWTP modelling. Water Sci. Technol. 2016, 73, 969-982. [CrossRef]

33. Launder, B.; Spalding, D.B. Lectures in Mathematical Models of Turbulence; Academic Press Inc.: London, UK; New York, NY, USA, 1972; ISBN1 0124380506. ISBN2 9780124380509.

34. Saeed, S.; Ein-Mozaffari, F.; Upreti, S.R. Using computational fluid dynamics to study the dynamic behavior of the continuous mixing of Herschel-Bulkley fluids. Ind. Eng. Chem. Res. 2008, 47, 7465-7475. [CrossRef]

35. Sanin, D.F. Effect of solution physical chemistry on the rheological properties of activated sludge. Water Sa 2002, 28, 207-212. [CrossRef]

36. Tixier, N.; Guibaud, G.; Baudu, M. Effect of $\mathrm{pH}$ and ionic environment changes on interparticle interactions affecting activated sludge flocs: A rheological approach. Environ. Technol. 2003, 24, 971-978. [CrossRef] [PubMed]

37. Lotito, V.; Lotito, A.M. Rheological measurements on different types of sewage sludge for pumping design. J. Environ. Manag. 2014, 137, 189-196. [CrossRef] [PubMed]

38. Pevere, A.; Guibaud, G.; van Hullebusch, E.; Lens, P.; Baudu, M. Viscosity evolution of anaerobic granilar sludge. Biochem. Eng. J. 2006, 27, 315-322. [CrossRef]

39. Björn, A.; Shakeri Yekta, S.; Ziels, R.M.; Gustafsson, K.; Svensson, B.H.; Karlsson, A. Feasibility of OFMSW co-digestion with sewage sludge for increasing biogas production at wastewater treatment plants. Euro-Mediterr. J. Environ. Integr. 2017, 2, 10. [CrossRef]

40. Hiemenz, P.C.; Rajagopalan, R. Principles of Colloid and Surface Chemistry, 3rd ed.; Revised and Expanded; Marcel Dekker, Inc.: New York, NY, USA, 1997; ISBN 9780824793975.

41. Geankoplis, C.J. Transport Processes and Unit Operations, 3rd ed.; Prentice-Hall International, Inc.: Eaglewood Cliffs, NJ, USA, 1993; ISBN 013045253X.

(C) 2019 by the authors. Licensee MDPI, Basel, Switzerland. This article is an open access article distributed under the terms and conditions of the Creative Commons Attribution (CC BY) license (http://creativecommons.org/licenses/by/4.0/). 